\title{
A method for sizing submicrometer particles in air collected on Formvar films and imaged by scanning electron microscope
}

\author{
E. Hamacher-Barth ${ }^{1}$, K. Jansson ${ }^{2}$, and C. Leck ${ }^{1}$ \\ ${ }^{1}$ Department of Meteorology, Stockholm University, Stockholm, Sweden \\ ${ }^{2}$ Department of Materials and Environmental Chemistry, Stockholm University, Stockholm, Sweden \\ Correspondence to: E. Hamacher-Barth (evelyne@ misu.su.se)
}

Received: 21 May 2013 - Published in Atmos. Meas. Tech. Discuss.: 19 June 2013

Revised: 4 November 2013 - Accepted: 7 November 2013 - Published: 10 December 2013

\begin{abstract}
A method was developed to systematically investigate individual aerosol particles collected onto a polyvinyl formal (Formvar)-coated copper grid with scanning electron microscopy. At very mild conditions with a low accelerating voltage of $2 \mathrm{kV}$ and Gentle Beam mode aerosol particles down to $20 \mathrm{~nm}$ in diameter can be observed. Subsequent processing of the images with digital image analysis provides size resolved and morphological information (elongation, circularity) on the aerosol particle population. Polystyrene nanospheres in the expected size range of the ambient aerosol particles (20-900 $\mathrm{nm}$ in diameter) were used to confirm the accuracy of sizing and determination of morphological parameters. The relative standard deviation of the diameters of the spheres was better than $\pm 10 \%$ for sizes larger than $40 \mathrm{~nm}$ and $\pm 18 \%$ for $21 \mathrm{~nm}$ particles compared to the manufacturer's certificate.

Atmospheric particles were collected during an icebreaker expedition to the high Arctic (north of $80^{\circ}$ ) in the summer of 2008. Two samples collected during two different meteorological regimes were analyzed. Their size distributions were compared with simultaneously collected size distributions from a Twin Differential Mobility Particle Sizer, which confirmed that a representative fraction of the aerosol particles was imaged under the electron microscope. The size distributions obtained by scanning electron microscopy showed good agreement with the Twin Differential Mobility Sizer in the Aitken mode, whereas in the accumulation mode the size determination was critically dependent on the contrast of the aerosol with the Formvar-coated copper grid. The morphological properties (elongation, circularity) changed with the number of days the air masses spent over the pack-ice
\end{abstract}

area north of $80^{\circ}$ before the aerosol particles were collected at the position of the icebreaker and are thus an appropriate measure to characterize transformation processes of ambient aerosol particles.

\section{Introduction}

Aerosol particles are ubiquitous in the troposphere and have a major influence on global climate and climate change (IPCC, 2007). Their direct effect on climate is through scattering and absorption of both incoming light from space and thermal radiation emitted from the Earth's surface (Andreae and Crutzen, 1997; Haywood and Boucher, 2000). The indirect effect is related to the role of aerosol particles as potential cloud condensation nuclei (CCN) (Twoomey, 1959; Baker, 1997; Lohmann and Feichter, 2005). The number, size, morphology, state of mixture and chemical composition of $\mathrm{CCN}$ will determine the number and size of cloud droplets and thus will be important factors that determine the optical properties of clouds (Charlson et al., 1992). Furthermore, aerosol particles serve as a source of ice nuclei and thereby contribute to the formation of mixed phase clouds (McFarquhar et al., 2013), which are frequently observed not only in the Arctic but also at lower latitudes (Shupe et al., 2008). The processes involved in cloud formation, however, are still not fully understood and not very well represented by current climate models, mainly due to a lack of observational data (IPCC, 2007).

The atmosphere contains significant concentrations of aerosol particles with a diameter size span ranging from 
a few nanometers to a few micrometers. It is therefore convenient to describe particle size as one single number. However, unless the particle is a perfect sphere, which is rare in natural atmospheric samples (Bigg and Leck, 2001a), there are many ways, including shape/morphology, degree of compactness, state of mixture and particle texture, to describe an aerosol particle (Coz and Leck, 2011). The only method at present to derive size resolved mapping of single particles including the above parameters, down to sizes in the lower nanometer range, is electron microscopy (Bigg et al., 2004; Laskin et al., 2006; Kandler et al., 2007; Coz et al., 2008; Leck and Bigg, 2008; Capanelli et al., 2011; Coz and Leck, 2011).

When particles collected onto a thin film of carbon or polyvinyl formal (Formvar), supported by a $3 \mathrm{~mm}$ transmission electron microscopy (TEM) copper $(\mathrm{Cu})$ grid, are imaged under the electron microscope, the electron beam is scattered to a higher degree in thicker and denser particulate material than in the uniform grid film. The images usually have good contrast and excellent resolution in two dimensions. Three-dimensional (3-D) resolution of particles can be obtained by shading the grid surface with fine metal coatings under a low angle (Bigg and Leck, 2001a). But shading the particles will slightly increase their size which in turn will result in a false size number distribution and move the size limit of detection to larger sizes. Without shading, parts of the sample and the Formvar film might on the other hand be destroyed by the high energy electron beam ( $80-200 \mathrm{kV})$ usually in operation.

Scanning electron microscopy (SEM) has been used for more than $50 \mathrm{yr}$ to image surfaces and particles (Junge, 1952; Parungo and Nagamoto, 1986; Stevens et al., 2009) and can be operated at an accelerating voltage as low as $1 \mathrm{kV}$. This enables highly detailed imaging of beam sensitive particles without radiation damage. Information on size, morphology, state of mixture and elemental chemical composition is available without distortion from metal shading. Particle size and morphological parameters can be a resolved down to $2-5 \mathrm{~nm}$ diameters while chemical elements can be mapped down to $50-100 \mathrm{~nm}$ diameters, but at a higher accelerating voltage. Microscopic methods, however, are tedious and time consuming and great progress has been made to develop automated scanning methods in the submicron size range (Poelt et al., 2002; Ocker et al., 1995). But these automated methods require a highly plain substrate and sufficiently good contrast between the aerosol particles and their background (Poelt et al., 2002). To ensure that the collected ambient aerosol particles are imaged over all size ranges, without any disturbances by stigmatism or defocusing, the aerosol samples must be scanned manually. Nevertheless, microscopic methods are not completely quantitative, and the availability of an objective and quantitative method for the evaluation of aerosol samples and microscope images is therefore a prerequisite for a systematic investigation. Moreover, to assess any direct or indirect aerosol effects on cloud formation and regional climate the aerosol population under investigation has to form a representative fraction of the collected ambient aerosol particles.

Here we present a quantitative method to systematically investigate single aerosol particles collected on Formvar film supported by a copper grid, with a SEM operating at low accelerating voltage. To maximize the surface information on the aerosol particles under investigation, a relatively low accelerating voltage of $2 \mathrm{kV}$ was applied and secondary electrons were detected. Electron microscopy generally has to handle the conflict between sufficiently high spatial resolution which depends on the probe size determined by the accelerating voltage and on the other hand electron radiation damage due to the high electron energy of the probe (Terasaki et al., 2013). Therefore, a stage bias was applied which reduced the impact electron energy onto the specimen (Michael et al., 2010) and to reduce the interaction volume that generates secondary electrons and to minimize radiation damage and charging problems (Terasaki et al., 2013). These conditions allow for the observation of the substrate surface at high resolution. Subsequent processing of the images with digital image analysis provides statistically size resolved information on the particle population collected on the film. Polystyrene latex (PSL) standard spheres were used to determine the errors in sizing the aerosol particles with SEM and subsequent digital image analysis.

Furthermore, the size distributions derived from the evaluation of microscope images of the PSL spheres and collected ambient samples were compared with simultaneously collected number particle size distributions seen by a Twin Differential Mobility Particle Sizer (TDMPS; Heintzenberg and Leck, 2012) and problems associated with the size determination of natural samples are identified and discussed. The ambient samples used in this study were collected in the high Arctic summer during the Arctic Summer Cloud Ocean Study (ASCOS) 2008 (www.ascos.se; Tjernström et al., 2013). The samples were obtained during a three-week period while the Swedish icebreaker Oden was anchored to a drifting ice floe close to the North Pole, around $87^{\circ} \mathrm{N}$.

\section{Methods for image recording and digital analysis}

\subsection{Scanning electron microscopy (SEM)}

The samples were investigated with a high-resolution SEM (JEOL JSM-7401F) under high vacuum conditions, at less than $9.63 \times 10^{-5} \mathrm{~Pa}$ (Stevens et al., 2009). The electron beam was generated by a cold field emission gun operating with an extracting voltage of $6.8 \mathrm{kV}$ which yielded an emission of $20 \mu \mathrm{A}$. The focused electron probe current was $16 \mathrm{pA}$ and secondary electrons emitted from the sample surface were detected with an in-lens column detector. A negative bias $(-2 \mathrm{kV})$ was applied on the sample stage to decelerate incident electrons before entering the sample surface. To 
generate a landing energy corresponding to $1 \mathrm{kV}$, a column accelerating voltage of $3 \mathrm{kV}$ was used. This Gentle Beam mode was used to minimize radiation damage, surface charge up and to demagnify the electron beam diameter (Michael et al., 2010). Images were recorded after correction of stigmatism and focusing and automatic adjustment of greyscale (contrast and brightness). Particle samples were collected directly onto a $3 \mathrm{~mm}$ TEM copper 300 mesh grids, coated with a 30-60 nm thick Formvar film (TED PELLA INC.).

\subsection{Grid screening protocol}

To image a representative fraction of the particle population collected on the Formvar film, each grid was screened systematically. Each grid was divided into four quadrants using the grid marker in the center of the grids (Fig. 1i). The screening of a grid started from the grid marker and went outwards towards the edge of the grid following each of the quadrant's (a, b, c or d) diagonal (i.e., 1,1; 2,2; 3,3, etc). Following the diagonals accounted for inhomogeneous particle distribution across the grid and aimed to image a representative particle distribution. In total between 7 and 9 squares were scanned, and between 300 and 500 images were obtained per grid. To reduce the screening time and to obtain a sufficient number of images for digital image analysis the scanning of the grid started from a low magnification $(80 \times)$. The whole grid was scanned in order to determine the orientation and to identify damaged areas, and proceeded via magnification of $1100 \times$ to take an image of the respective square in the copper grid, and finally images at $10000 \times$ and $40000 \times$ were recorded (Fig. 1). The images at $40000 \times$ were used for digital imaging processing. Focus and stigmatism were controlled and corrected frequently before the images were taken.

\subsection{Digital image analyses}

Digital image analysis involves all processes that are necessary to extract information from a digital image: image processing, separation of the object (the aerosol particle) from the background, and measurement of the desired parameters. Microscope images at $40000 \times$ were evaluated using an optimized commercial image processing software (Aphelion ${ }^{\text {TM }}$ Dev 4.10). In addition to size we use two morphological parameters to extend the description of the mapped particles. These parameters (elongation and circularity) provide a measure of the deviation from spherical geometry and can be directly addressed by the image processing software.

\subsubsection{Separation of particles from the background}

To reduce the background noise of the digital image obtained with SEM an automedian filter and subsequently a Gauss filter $(3 \times 3)$ were applied to each image. To separate the imaged aerosol particle from its background the maximal intensity of the neighboring background has to be determined. Therefore an image section of the particle background was produced with a size of about $250 \times 250$ pixels by cutting out the aerosol particle (Fig. 2i, area inside the dashed rectangle) and to determine the maximal background intensity (Fig. 2i). Using exactly the same image but including the aerosol particle allowed the separation of the particle and measurement of the particle area (Fig. 2ii; in pixels). The threshold was set to $40 \%$ of the intensity difference between background and aerosol maximal intensity (Fig. 3). This value was chosen subjectively with respect to the often weakly contrasting particles and determined manually by comparing results from threshold values between $5 \%$ and $50 \%$.

\subsubsection{Particle size}

The size of an aerosol particle can be expressed as the particle equivalent diameter $\left(D_{\mathrm{pa}}\right)$ according to Eq. (1).

$D_{\text {pa }}=2 \sqrt{\text { Area } / \pi}$

The particle equivalent diameter $D_{\mathrm{pa}}$ is the diameter of a circle that comprises the same area as the projected particle. The value for the area is calculated from the number of pixels (Area) counted for each particle (Allen, 1997; Hinds, 1999).

From the particle area (in pixels) the diameter of an equivalent sphere for each aerosol particle was derived with help of Eq. (1). A number size distribution of the aerosol sample was obtained by calculating a histogram using MATLAB 2011a and the freely available software package EasyFit.

\subsubsection{Morphological properties}

The morphological properties of the particles have been quantified by the following parameters:

- Circularity is sensitive to both overall form and surface roughness, showing values in the range from 0 to 1 . A perfect circle has a circularity of 1 while a very irregular object has a circularity value close to 0 (Fig. 4).

Circularity $=4 \pi$ Area $/ \mathrm{CP}^{2}$

Circularity uses the Crofton perimeter (CP), which is calculated according to Eq. (3).

$\mathrm{CP}=\pi \sum_{i=1}^{n} N_{i}\left(X, k_{i}\right)$

where $N_{i}$ is the intercept of $X$ in the orientation $\omega_{i}$ and $k_{i}$ is a coefficient to correct for the bias depending on the orientation of the particle on the image. Aphelion ${ }^{\mathrm{TM}}$ 4.10 uses 4 orientations $\left(\omega_{0}=0^{\circ}, \omega_{1}=45^{\circ}, \omega_{2}=90^{\circ}\right.$ and $\left.\omega_{3}=135^{\circ}\right) ; k_{0}$ and $k_{2}$ equal 1 , whereas $k_{1}$ and $k_{3}$ equal $1 / \sqrt{ } 2$. An intercept is the number of transitions from intensity to non-intensity in a given orientation (Fig. 5; Serra, 1988; Meyer, 1990). 


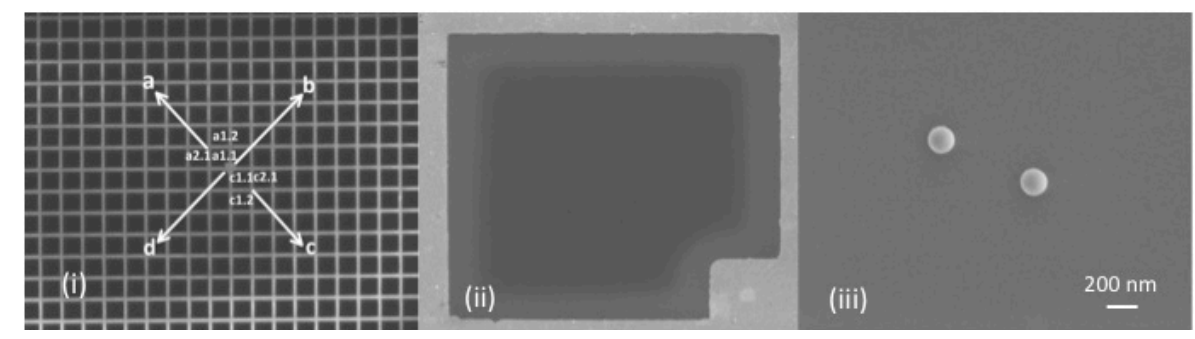

Fig. 1. (i) a copper grid imaged using SEM at $80 \times$ magnification showing the grid marker at center and definition of the square labeling in quadrant a and c, (ii) the single grid square (a1,1) imaged at $1100 \times$ magnification, (iii) particles imaged at $40000 \times$ magnification.
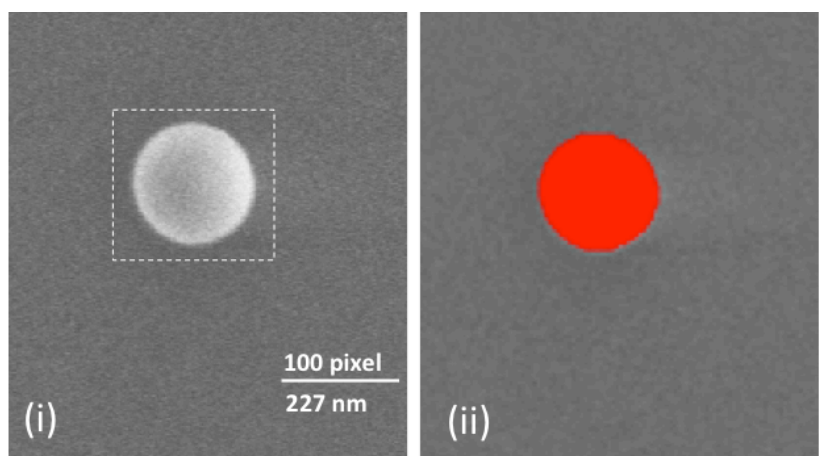

Fig. 2. (i) image for determination of the background intensity and (ii) corresponding digital image used in measurement of particle size and morphological parameters.

- Elongation is sensitive to the overall form of a particle and is calculated according to Eq. (2).

$$
\text { Elongation }=\left(D_{\max }-D_{\min }\right) /\left(D_{\max }+D_{\min }\right)
$$

$D_{\max }$ is the longest projection of the particle, $D_{\min }$ is the shortest projection. Elongation is close to zero for compact particles and close to 1 for open branched ones. The larger the ratio between $D_{\max } / D_{\min }$ the closer to 1 the value for elongation becomes (Fig. 4); for a particle with $D_{\max } / D_{\min }=1000: 1$ the elongation is calculated to 0.998 .

\section{Methods for sampling of airborne aerosol particles during ASCOS}

Scanning electron microscopy with subsequent image mapping (Sects. 2 and 4) was applied to two ambient aerosol samples (see Sect. 5.1 for details) collected onboard the Swedish icebreaker Oden in the course of ASCOS. The expedition focused on the formation and life cycle of low-level Arctic clouds with linkages to the microbiological life in ocean and ice. ASCOS departed from Longyearbyen on Svalbard on 2 August and returned on 9 September. After traversing the pack ice northward an ice camp was set up on 12 August at

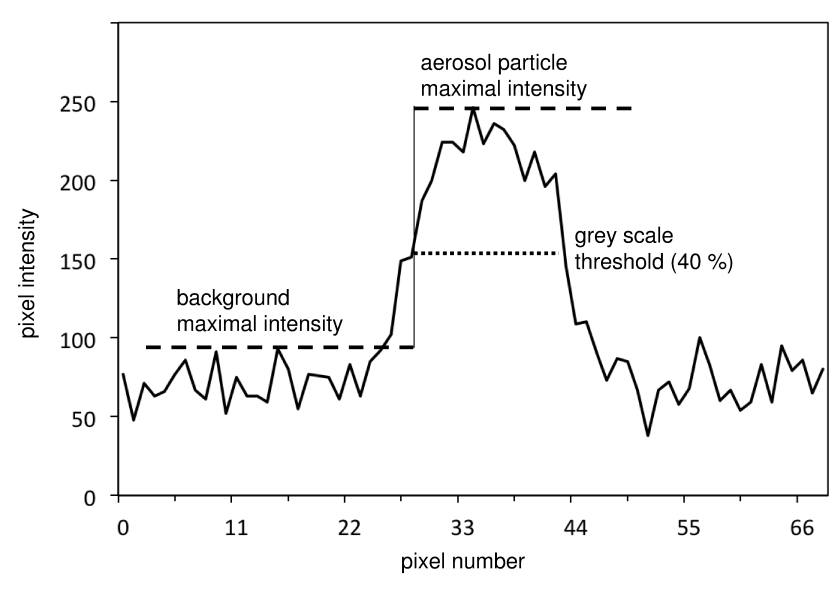

Fig. 3. Determination of aerosol particle size. Background and particle intensity were determined independently; the threshold for the determination of the particle size was set at $40 \%$ of the intensity difference between background and aerosol particle maximal intensity.

$87^{\circ} \mathrm{N}$ and remained in operation through 1 September, drifting with the ice. Tjernström et al. (2013) documented the ASCOS instrument suite in detail. Key methods for sampling used in this study are described below.

\subsection{The sampling manifold}

A $\mathrm{PM}_{10}$-inlet (diameter $<10 \mu \mathrm{m}$ at ambient relative humidity, $\mathrm{RH})$ was placed upstream of all aerosol measurements located in a laboratory container on the fourth deck of the icebreaker. The aerosol inlet was designed to optimize the distance from the sea and from the ship's superstructure and was located $\sim 25 \mathrm{~m}$ above the sea surface and $3 \mathrm{~m}$ above the roof of the laboratory container. Direct contamination from the ship was excluded by using a pollution controller. Provided that the wind was within $\pm 70^{\circ}$ of the direction of the bow and stronger than $2 \mathrm{~m} \mathrm{~s}^{-1}$, no pollution reached the sample inlets (Leck et al., 1996). To maximize the sampling time it was necessary to face the ship into the wind. More details of the set-up for the sampling of aerosol particles are given in Leck et al. (2001). 


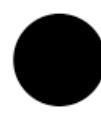

Circularity = 1

Elongation $=0$

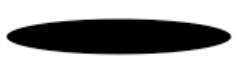

Circularity $=0.47$

Elongation $=0.66$

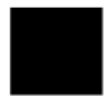

Circularity $=0.89$

Elongation $=0.17$

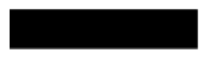

Circularity $=0.52$

Elongation $=0.66$

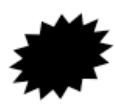

Circularity $=0.47$

Elongation $=0.14$

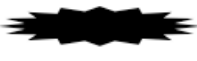

Circularity $=0.21$

Elongation $=0.69$

Fig. 4. Illustration of the morphological descriptors and elongation circularity (Huck, 2013, modified).

The aerosol samples were drawn into the aerosol inlet at an ambient relative humidity of $85-100 \%$ and temperatures of about $0{ }^{\circ} \mathrm{C}$ (Tjernström et al., 2012). Directly after the inlet tube passed the container roof the air was distributed to the TDMPS and the electrostatic precipitator for sampling onto the TEM grids with a short stainless steel tube of $1 \mathrm{~m}$ length. The temperature in the container was kept at $20^{\circ} \mathrm{C}$ which resulted in a RH of $20 \%$ when the sampling onto the TEM grid occurred. These relative dry conditions are commonly chosen for sampling of aerosol particles and were the same for the TDMPS instrument and the electrostatic precipitator. Both instruments were placed close together along the inlet to ensure that sampling conditions and losses were the same for both instruments.

Volatile organic compounds on the particle surface as well as weakly bound water molecules (see discussion below) are probably lost during the sampling procedure and require other measurement techniques to capture them. In the Arctic the concentration of volatile organic compounds in the atmosphere is generally lower than at lower latitudes (Bates et al., 1987) and thus the losses due to evaporation during our measurements can be considered to be very small.

\subsection{Collection of particles for subsequent single particle mapping by SEM}

Airborne aerosol particles were collected directly onto the Formvar-coated $\mathrm{Cu}$ TEM grids with an electrostatic precipitator (Dixkens and Fissan, 1999; Leck and Bigg, 2008). The particles were charged at the aerosol inlet by a ${ }^{63} \mathrm{Ni}$ betaemitting radioactive source and afterwards precipitated by a $12 \mathrm{kV} \mathrm{cm}^{-1}$ electric field between the inlet and the collecting surface. The flow rate was kept very low $\left(0.17 \mathrm{~mL} \mathrm{~s}^{-1}\right)$ in order to collect particles up to $\sim 1 \mu \mathrm{m}$. The collection efficiency of the electrostatic precipitator was inter-compared with the TSI 1236 Nanometer Aerosol Sampler ( ${ }^{63} \mathrm{Ni}$ betaemitting radioactive source and sample flow of $1 \mathrm{~L} \mathrm{~m}^{-1}$ ) mounted side-by-side with the electrostatic precipitator. Both collected a small, but statistically significant number of particles $<25 \mathrm{~nm}$. The precipitator took samples for 6 to $12 \mathrm{~h}$. Before and after sampling the grids were placed within a grid

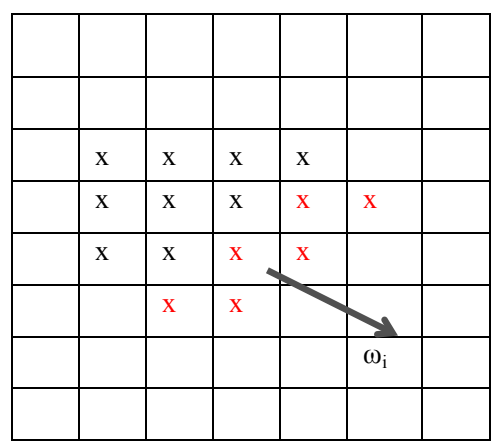

Fig. 5. Schematic representation of the calculation of the Crofton perimeter. The pixels with transitions from intensity to non-intensity are shown in red, $\omega_{i}$ is the orientation along which the number of intercepts $N_{i}$ are calculated.

holder box in a sealed dry plastic bag, together with silica gel packets, and stored in a desiccator at a constant temperature of $20^{\circ} \mathrm{C}$ before they were investigated.

\subsection{Number size distributions using a TDMPS}

The sampling system to measure the number size distributions of dry submicrometer particles used pairs of differential mobility analyzers (DMAs). The TSI 3010 counters in the DMAs were size and concentration calibrated against an electrometer and the TSI 3025 counters for particle sizes below $20 \mathrm{~nm}$ diameter according to Stolzenburg (1988). This set-up yielded a complete number size distribution from $3 \mathrm{~nm}$ to $800 \mathrm{~nm}$ diameter in 45 intervals of diameter every 10 min. Further details of the TDMPS system can be found in Heintzenberg and Leck (2012). NIST (National Institute of Standards Technology) traceable calibration standards of polystyrene latex (PSL) spherical particles were used to determine error in determination of the mobility diameter to $\pm 5 \%$ (Wiedensohler et al., 2012).

Number size distributions obtained from TDMPS measurements were adapted to SEM measurements by taking the median value for each of the 45 TDMPS size intervals by assuming the same particle diameter in the respective interval. The particle diameters were then merged to form a complete set of diameters across the TDMPS measuring interval. The data were then treated in the same way as the SEM derived data to obtain a number size distribution.

\section{Polystyrene latex spheres used for SEM calibration}

To determine the error on sizing with the SEM a range of NIST PSL spherical particles was investigated. The diameter values obtained with SEM/image mapping were compared with the values obtained by the manufacturer, and morphological parameters (circularity, elongation) were determined. The sizes of the standards were chosen to cover the size 

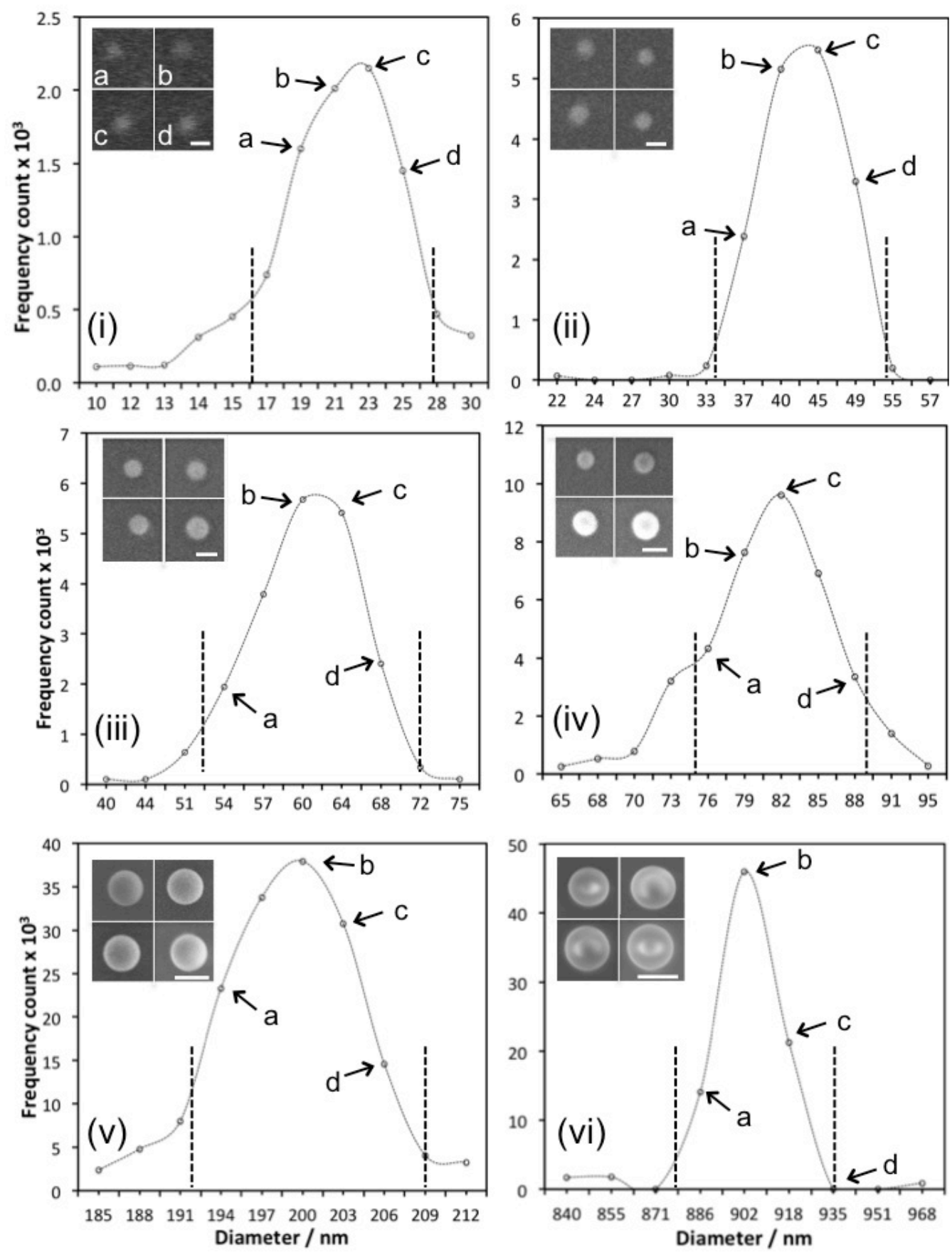

Fig. 6. Size distributions obtained for PSL spheres: (i) $21 \mathrm{~nm}$, (ii) $40 \mathrm{~nm}$, (iii) $60 \mathrm{~nm}$, (iv) $80 \mathrm{~nm}$, (v) $200 \mathrm{~nm}$, and (vi) $900 \mathrm{~nm}$. The dashed lines indicate the diameter boundary values for statistical analysis and the determination of morphological parameters. The insets show examples for the respective PSL spheres, and the calibration bars represent $20 \mathrm{~nm}$ (i), $40 \mathrm{~nm}$ (ii), $60 \mathrm{~nm}$ (iii), $80 \mathrm{~nm}$ (iv), $200 \mathrm{~nm}$ (v), and $900 \mathrm{~nm}$ (vi).

distribution of a remote marine atmospheric aerosol population in the submicrometer size range (Covert et al., 1996; Heintzenberg and Leck, 2012) as a superposition of more or less distinguishable modes, and PSL spheres of the following diameters were used: $21 \pm 1 \mathrm{~nm}, 40 \pm 1 \mathrm{~nm}, 57 \pm 4 \mathrm{~nm}$, $81 \pm 3 \mathrm{~nm}, 200 \pm 6 \mathrm{~nm}$, and $903 \pm 12 \mathrm{~nm}$.

\subsection{Sample preparation}

To prepare the grid standards for subsequent screening and evaluation, the bottle containing the microspheres (all polymer microsphere suspensions were purchased from Thermo Scientific) was gently inverted several times to disperse the microspheres and then immersed in an ultrasonic bath at 
$45 \mathrm{~Hz}$. Two droplets of the $1 \%$ microsphere suspension were further suspended in $250 \mathrm{~mL}$ deionized water (Millipore Alpha-Q, resistivity $18 \mathrm{M} \Omega \mathrm{cm}$ ) and stirred gently. A TEM Formvar grid was placed on a $0.8 \mu \mathrm{m}$ pore size Millipore filter (type AA), which was lying upon a nutrient pad (the porous filter material used to hold nutrients in bacterial cultures) in contact with deionized water. A volume of $2 \mu \mathrm{L}$ of the microsphere suspension was applied onto the surface of the grid with a hypodermic syringe. The grid, filters and water were kept in a fume hood for $24 \mathrm{~h}$ to allow the water and soluble material to diffuse through the plastic film into the water phase. The grid was subsequently stored in a desiccator until further SEM imaging.

\subsection{Sizing results}

The diameters of the PSL particles were in the range of the manufacturer's size specifications; for the $21 \pm 1 \mathrm{~nm}$ spheres a diameter of $22.5 \mathrm{~nm}$ with a standard deviation of $\pm 4.1 \mathrm{~nm}$ was determined. The larger spheres showed successively smaller relative standard deviations: $42.7 \pm 4.1 \mathrm{~nm}, 60.8 \pm$ $4.5 \mathrm{~nm}, 81.9 \pm 4.6 \mathrm{~nm}, 199.7 \pm 5.2 \mathrm{~nm}$ and $903.9 \pm 13.1 \mathrm{~nm}$ (Table 1). Generally the diameter for each of the PSL sphere sizes shows a good agreement with the size the manufacturer states in the NIST certificate following each of the PSL sphere sizes (Figs. 6 and 7). The size distributions obtained with SEM imaging are monomodal with median values and standard deviations as listed in Table 1. The magnitude of the relative standard deviation decreased with the increase of the sphere diameter, from $18 \%$ for $20 \mathrm{~nm}$ spheres to $1.3 \%$ for $900 \mathrm{~nm}$ spheres. The same trend was observed for elongation and circularity of the spheres, as these values decrease continuously from $16 \%$ deviation from the elongation for a perfect sphere for $20 \mathrm{~nm}$ spheres to $0.13 \%$ deviation for $900 \mathrm{~nm}$ spheres. The values for circularity are closer to ideal circularity for a perfect sphere for the $900 \mathrm{~nm}$ spheres $(0.2 \%$ deviation) than for the $20 \mathrm{~nm}$ spheres (7\% deviation, Table 1).

\subsection{Determination of size limit of detection}

At a magnification of $40000 \times$ each pixel in the digital images has a size of $2 \mathrm{~nm} \times 2 \mathrm{~nm}$. By assuming that the electron beam diameter is optimized with respect to focus and stigmatism, a diameter of $1 \mathrm{~nm}$ will be obtained. Under this condition the observed size limit of detection in the images will be $5-10 \mathrm{~nm}$ in diameter. By use of $3 \times 3$ pixels to separate a particle from the background in the digital image analysis the theoretical minimum diameter of particles that can be detected is $6 \mathrm{~nm}$. At lower magnification the pixel size and thus the particle diameter that can be determined increases. At $10000 \times$ the pixel size is $8 \mathrm{~nm}$ and the theoretical minimum diameter is $24 \mathrm{~nm}$.

The real size limitation of particle detection also depends on the element composition of both particle and substrate, and the magnitude of accelerating voltage that generates the
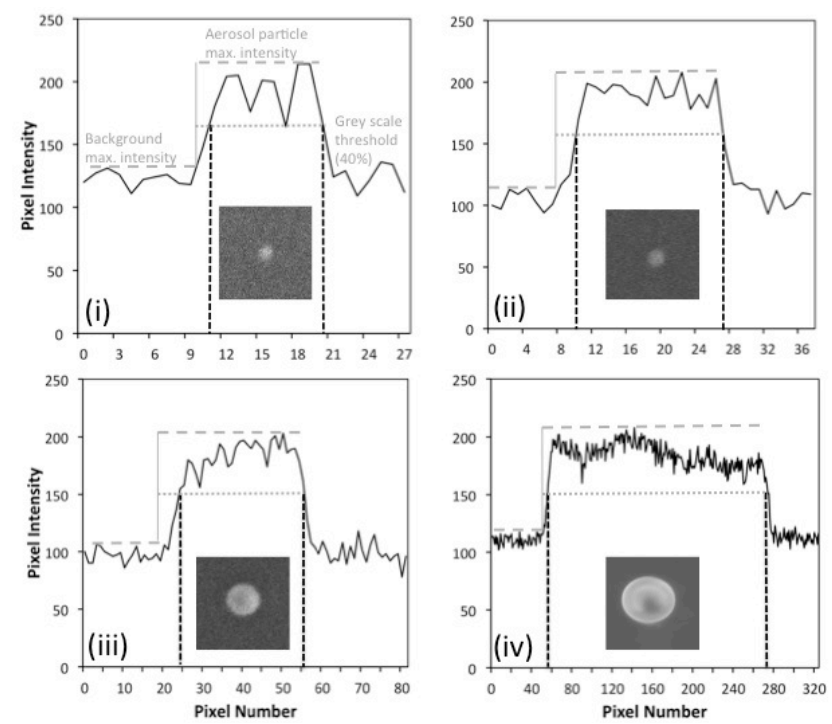

Fig. 7. Pixel intensities vs. pixel number for (i) $20 \mathrm{~nm}$ PSL spheres, (ii) $40 \mathrm{~nm}$ PSL spheres, (iii) $80 \mathrm{~nm}$ PSL spheres and (iv) $900 \mathrm{~nm}$ PSL spheres. The dashed lines indicate the boundaries for the determination of the background grey level threshold values.

electron beam interaction volume. Summarizing these factors the size limit of detection for PSL particles is $15 \mathrm{~nm}$ at a magnification of $40000 \times$.

\section{Airborne aerosol samples imaged by scanning electron microscope}

Studies of atmospheric aerosol properties resolved over size within the Arctic pack-ice area are sparse. The in situ data archives include essentially only the observations of ASCOS 2008 and three previous research expeditions onboard the Swedish icebreaker Oden in the summers of 1991, 1996 and 2001 (Leck et al., 1996, 2001, 2004; Tjernström et al., 2004). In summer the air over the Arctic pack-ice area is generally very clean and aerosol number concentrations are low (ca. $100 \mathrm{~cm}^{-3}$ ) because the air mass transport from strong midlatitudinal polluted regions into the Arctic is limited (Lannefors et al., 1983; Leck et al., 1996; Heintzenberg et al., 2006; Heintzenberg and Leck, 2012). Nevertheless, the size distributions of aerosol particles have shown high variability, but generally appeared as a superposition of more or less distinguishable modes (Covert et al., 1996; Heintzenberg and Leck, 2012). Each of these modes can be represented by a lognormal distribution (Whitby, 1978; Hoppel et al., 1986). Nucleation mode particles with sizes less than $10 \mathrm{~nm}$ in diameter are relatively common in the boundary layer of the central Arctic Ocean during summer (Wiedensohler et al., 1996; Leck and Bigg, 1999, 2010; Karl et al., 2013). At diameters $>10 \mathrm{~nm}$, particle number concentrations show a maximum somewhere between $25 \mathrm{~nm}$ and $80 \mathrm{~nm}$, depending 
Table 1. Diameter and the morphological parameters, elongation and circularity, of PSL spheres derived by digital image analysis of SEM images at $40000 \times$. In brackets the relative magnitude of the standard deviation, the relative deviation from elongation and circularity of an ideal sphere.

\begin{tabular}{lrrrrrr}
\hline & $21 \mathrm{~nm}$ & $40 \mathrm{~nm}$ & $60 \mathrm{~nm}$ & $80 \mathrm{~nm}$ & $200 \mathrm{~nm}$ & $900 \mathrm{~nm}$ \\
\hline Certificate & $21 \pm 1 \mathrm{~nm}$ & $40 \pm 1 \mathrm{~nm}$ & $57 \pm 4 \mathrm{~nm}$ & $81 \pm 3 \mathrm{~nm}$ & $200 \pm 6 \mathrm{~nm}$ & $903 \pm 12 \mathrm{~nm}$ \\
Measured & $22.5 \pm 4.1 \mathrm{~nm}$ & $42.7 \pm 4.1 \mathrm{~nm}$ & $60.8 \pm 4.5 \mathrm{~nm}$ & $81.9 \pm 4.6 \mathrm{~nm}$ & $199.7 \pm 5.2 \mathrm{~nm}$ & $903.9 \pm 13.1 \mathrm{~nm}$ \\
& $(18 \%)$ & $(9.5 \%)$ & $(7.3 \%)$ & $(5.6 \%)$ & $(2.6 \%)$ & $(1.4 \%)$ \\
Elongation (sphere $=0)$ & $0.16(16 \%)$ & $0.09(9 \%)$ & $0.05(5 \%)$ & $0.04(4 \%)$ & $0.03(3 \%)$ & $0.001(0.13 \%)$ \\
Circularity (sphere $=1)$ & $0.93(7 \%)$ & $0.93(7 \%)$ & $0.94(6 \%)$ & $0.94(6 \%)$ & $0.97(3 \%)$ & $0.998(0.2 \%)$ \\
\hline
\end{tabular}
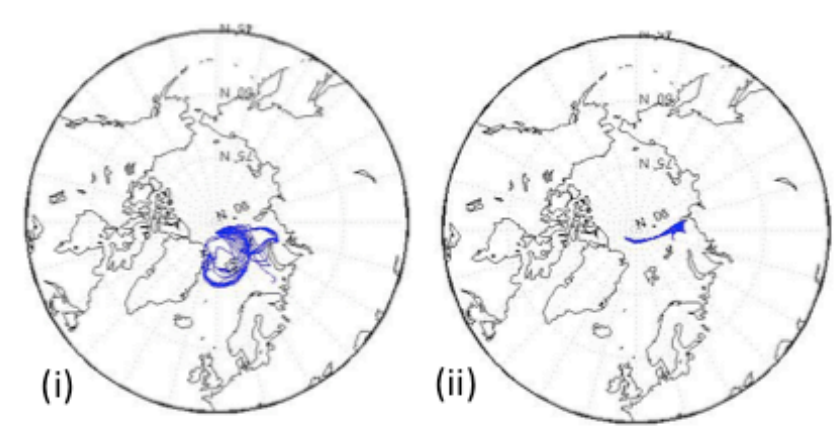

Fig. 8. Air mass trajectory clusters with an arrival height of $100 \mathrm{~m}$ at the position of the icebreaker during (i) 15 August originated easterly from the Greenland Sea and Barents Sea area, (ii) 19 August from the Kara Sea.

on the location (Kerminen and Leck, 2001; Leck and Bigg, 2005a, b; Heintzenberg and Leck, 2012). This Aitken mode results from condensational growth of nucleation mode particles as well as from primary marine biogenic emissions (Leck and Bigg, 2010; Orellana et al., 2011; Karl et al., 2013). A concentration minimum, referred to as the Hoppel minimum, follows at about $80 \mathrm{~nm}$ in diameter. An accumulation mode, appears between 100 and $200 \mathrm{~nm}$, and typically results from condensation of gases, such as the oxidation products of dimethyl sulfide (sulfuric and methane sulfonic acids), on preexisting Aitken mode particles (Kerminen and Leck, 2001; Karl et al., 2013) and from the formation of particle mass by in-cloud chemistry via sulfur dioxide. Furthermore primary particles, both biogenic and sea salt, can be directly injected into the accumulation mode and into the larger coarse mode (above $1000 \mathrm{~nm}$ in diameter) by bubble bursting at the sea-air interface (Leck et al., 2002; Leck and Bigg, 2005a; Bigg and Leck, 2008). The coarse mode is often inconspicuous in a number size distribution but contributes substantially to aerosol volume/mass.

\subsection{The approach applied to two aerosol samples collected during ASCOS}

The first sample (Sample A) was collected between 15:55 and 22:46 UTC (total sampling time 6:51 h) on 15 August.
This time period was dominated by air masses originating from the Greenland and Barents Sea area (Fig. $8 \mathrm{i}^{1}$ ). The second sampling period (Sample B, 19 August from 08:20 until 16:46 UTC, total sampling time $8: 26 \mathrm{~h}$ ) was dominated by air that had been advected from the Kara Sea (Fig. 8ii). Both samples were collected at around $87^{\circ} \mathrm{N}$ but had spent different times over the pack-ice since their last contact with open sea. Days over ice (DOI) ${ }^{2}$ were determined to be 0.9 days for Sample A and to be 4.5 days for Sample B.

Both samples show a bimodal size distribution (Figs. 9 and 10) which is characteristic for an aerosol population that was modified by in cloud processing (Hoppel et al., 1986) and suggests an aerosol source from the marginal ice zone (MIZ) and/or open water further south. Air mass back trajectory clusters that show the origin of the air masses reaching the position of the icebreaker on the sampling date (Fig. 8) verify the origin of the air masses. Previous studies (Leck and Persson, 1996a, b; Leck et al., 2002; Leck and Bigg, 2005a, b; Bigg and Leck, 2008) confirm this bimodal distribution, which is the result of both primary (biogenic and sea salt) and secondary (dimethyl sulfide oxidation products, condensational growth and in-cloud oxidation) aerosol sources within the open leads between the pack ice and/or along the MIZ.

The previous high Arctic campaigns clearly show that ambient aerosol particles are not necessarily spherical but can show a very irregular shape and surface (e.g., Bigg and Leck,

\footnotetext{
${ }^{1}$ Computation of 10 days backward trajectories for the air mass arriving at $100 \mathrm{~m}$ altitude at the position of the icebreaker. The Hybrid Single Particle Lagrangian Integrated Trajectory Model (HYSPLIT) (Draxler and Rolph, 2011; Rolph, 2011) was used for the trajectory calculations based on data from the Global Data Assimilation System (GDAS) of the National Weather Service's National Centers for Environmental Prediction (NCEP).

${ }^{2}$ The time spent over the pack ice by the air mass since last contact with open sea (DOI) was calculated for the purposes of ASCOS as in Nilsson and Barr (1996) and uses the HYSPLIT back trajectories in combination with maps of sea ice distribution. The latter were created based on data from NSIDC, Boulder, CO, United States, obtained by the sensor onboard the Aqua satellite, with the final analysis being conducted at the University of Bremen, Germany. The measure of DOI represents thus a simple parameter to summarize the evolution of the aerosol particles as a function of the synoptic scale systems since their last contact with open sea.
} 


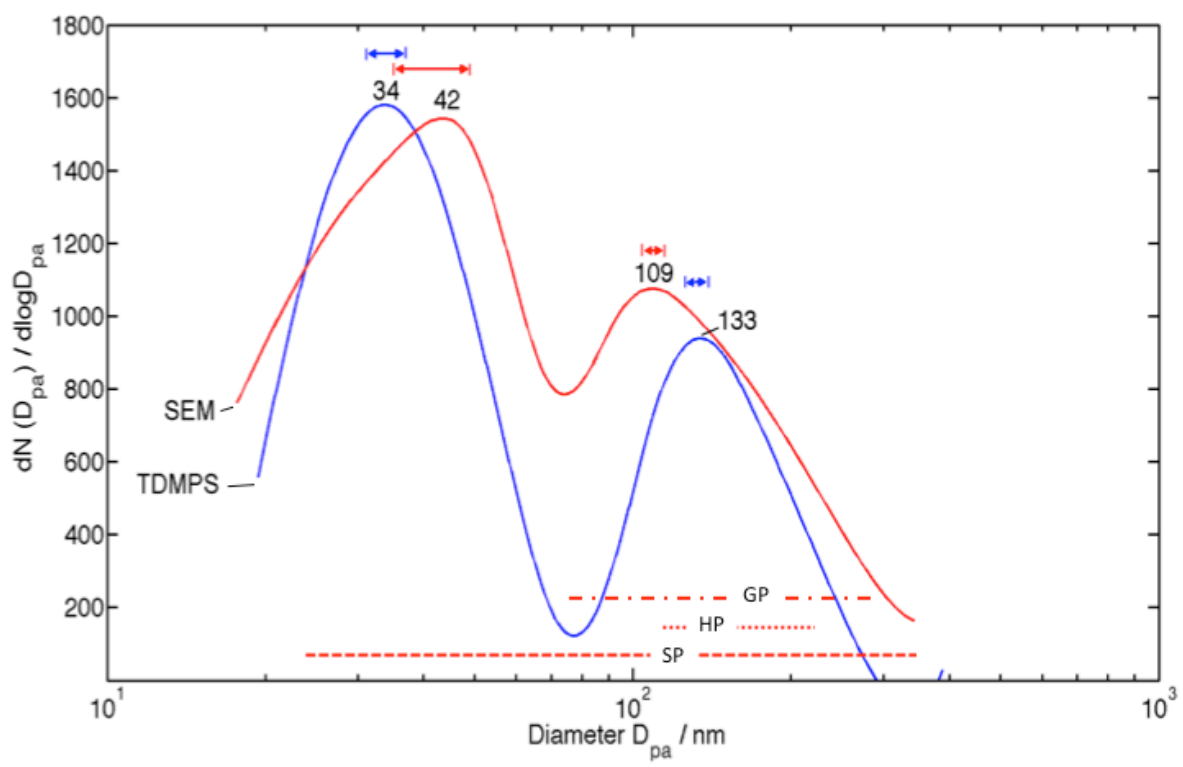

Fig. 9. Number size distributions obtained for Sample A. Red line - SEM derived particle number distribution, blue line - number size distribution from TDMPS measurements. The red bars represent the size ranges in which particle types appear in SEM: SP - dashed line, HP - dotted line, GP - dash-dot line; the arrows represent the ranges of uncertainty for the respective mode in each size distribution based on results from sizing of PSL spheres for SEM data, and $5 \%$ uncertainty for TDMPS measurements (Wiedensohler et al., 2012).

2001a). Freedman et al. (2010) discuss changes in aerosol particle shape and size after impaction onto a substrate. The two critical factors are the solubility of the aerosol particle outer layer and the polarity of the sampling substrate. Leck and Bigg (1999, 2005a, b) and Orellana et al. (2011) characterized the primary biogenic aerosol to be made up by polymer gels. Marine phytoplankton and sea-ice algae excrete these polymer gels. They are water insoluble, thermally stable, highly surface active and highly hydrated. The polymer molecules consist of polysaccharides which form threedimensional networks interlinked with divalent ions, preferably $\mathrm{Ca}^{2+}$, to which other organic compounds (proteins and lipids) can be readily bound. The non-water soluble properties have been attributed to hydrophilic and hydrophobic segments of the gels (Orellana et al., 2011) and are in agreement with their chemical behavior modeled by Xin et al. (2013). Facchini et al. (2008) described a similar type of gel particles collected over the North Atlantic which mainly contained water insoluble organic carbon $(94 \pm 4 \%)$ in the submicron range.

Assumed that the organic fraction of the samples collected for our study contain an equally high amount of water insoluble organic carbon as in Facchini et al. (2008) the aerosol particles can be characterized as mainly water insoluble. The sampling substrate on the other hand, the Formvar-coated $\mathrm{Cu}$ TEM grid, is hydrophilic and thus polar due to the chemical nature of the Formvar film (Rocha et al., 2005). The impaction of a water insoluble organic particle onto the polar Formvar film left the particle compact and retained its shape (Freedman et al., 2010). An impacting particle with a higher solubility splattered upon impaction onto the hydrophilic substrate and formed a high number of satellite particles. The more soluble the organic substance was the smaller and more numerous the satellite particles were. Based on these former studies it can be assumed that most of the gel particles imaged in our samples retained their initial morphology and size due to the specific physico-chemical interaction between sampling substrate and aerosol particle.

A change of morphology of the gel particles due to the dry ambient conditions during sampling and the high vacuum under the electron microscope can also be excluded. The gel particles are highly hydrated (up to $99 \%$ water), but the water molecules are mainly bound within the polymer gel structure and do not evaporate at dry ambient conditions. Only a relatively small number of molecules that are located on the surface of the marine gel particles can evaporate. But the evaporation of these surface bound water molecules does not affect the structure of the particles (Leck and Bigg, 2005b).

Three types of particles were observed in both Sample A and $\mathrm{B}$ :

- Single particles (SP): these particles consist of single entities with homogeneously distributed pixel intensity across the whole particle. They often contrast sharply and are relatively easy to separate from their background (Fig. 11). SP can be observed in the Aitken as well as in the accumulation mode size range. The single particles in the accumulation mode occasionally collapse under the electron beam but keep their outer shape, which is typical for ammonium sulfate particles 


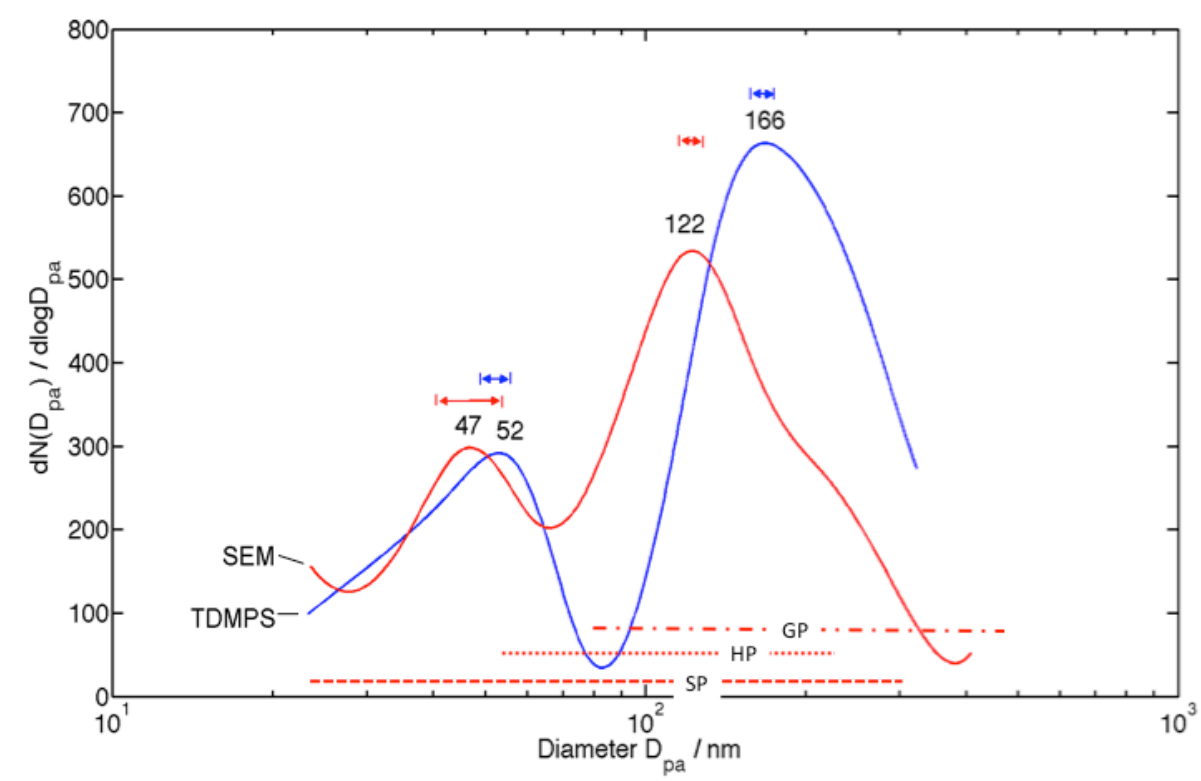

Fig. 10. Number size distribution obtained for Sample B. Red line - SEM derived particle number distribution, blue line - number size distribution from TDMPS measurements. The red bars represent the size ranges in which particle types appear in SEM: SP - dashed line, HP - dotted line, GP - dash-dot line. The arrows represent the ranges of uncertainty for the respective mode in each size distribution based on results from sizing of PSL spheres for SEM data, and $5 \%$ uncertainty for TDMPS measurements (Wiedensohler et al., 2012).

(Heard and Wiffen, 1969; Fig. 12). To avoid biases due to size changes, we imaged these particles as quickly as possible in order to minimize evaporative losses and beam damage and at the same time to optimize the contrast and surface information about the aerosol particles.

- Gel particles (GP): in contrast to SP these particles show a patchy, inhomogeneous distribution of pixel intensity (Fig. 13). This patchy appearance and the in some cases very weak contrast with the Formvar film suggest that GP are built up by material that consists predominantly of light elements $(\mathrm{C}, \mathrm{H}, \mathrm{N}, \mathrm{O})$ and forms a film-like structure on the Formvar film. This at times weakly contrasting film-like material on the Formvar film could possibly lead to an underestimation of the area of the GP deposited on the film surface. The majority of GP appears in the accumulation mode (Table 1).

- Halo particles (HP): a relatively large central particle is surrounded by a number of smaller satellite particles with $D_{\mathrm{pa}} / 10$ to $D_{\mathrm{pa}} / 3\left(D_{\mathrm{pa}}\right.$ : equivalent diameters derived from the projected area of the central particle using Eq. 1; Fig. 14). To establish the proportion of satellite particles in the HP, the area of in total 19 HP was calculated by manually determining the area (in pixels) of the central particle and the surrounding satellite particles on an image. By summing up these areas, the diameter of the hypothetically intact particle before impacting on the Formvar film and the proportion of the satellite particles were calculated. The satellite particles contributed to up to $45 \%$ to the $D_{\mathrm{pa}}$. However, the satellite particles are small and contrast very weakly; thus, they are difficult to capture with image processing and the determination of morphological parameters was restricted to the core particles. The weak contrast with the substrate can biases the overall particle diameters of HP with a satellite type appearance towards smaller values and might contribute to a difference of the accumulation mode number maximum in peak positions in the SEM and TDMPS derived size distributions.

The very different character of the aerosol particles and their partly irregular appearance require the use morphological parameters for further characterization. All three types of particles described above were investigated separately and the morphological descriptors elongation and circularity were determined for each type of particle in each sample.

To determine the uncertainty of our measurements, we refer to the results from both the number distribution as a function of equivalent diameters derived from the area of the projected particle $\left(D_{\text {pa }}\right)$ based on SEM and subsequent image mapping, and the number distribution as a function of mobility diameters $\left(D_{\mathrm{m}}\right)$ from the TDMPS data. The underlying assumption for both independent methods is that the particles are spherical. The air is in both applied methods sampled off the same sampling manifold, at the same RH $(20 \%)$ and charged with the same ${ }^{63} \mathrm{Ni}$ - emitting radioactive 


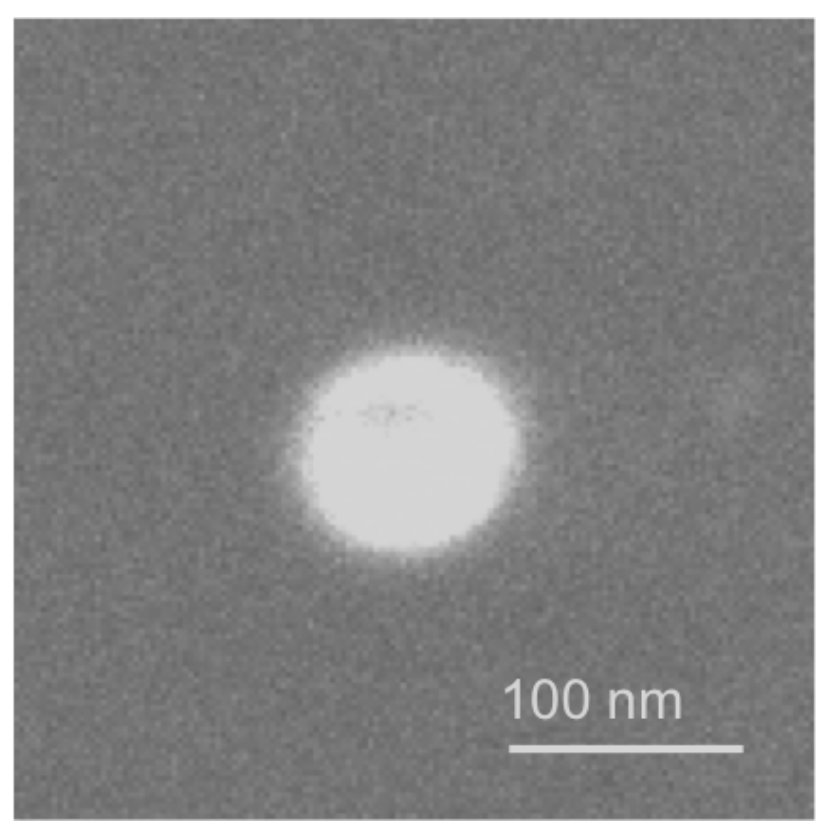

Fig. 11. An example for a single particle (SP) with homogeneously distributed pixel intensity across the aerosol particle.

source. Both methods were calibrated against NIST traceable calibration standards of polystyrene latex spherical particles. The error of sizing (relative standard deviation) for the independent TMPS is less than $5 \%$ (Wiedensohler et al., 2012), whereas for the SEM an error of sizing between $18 \%$ for $20 \mathrm{~nm}$ spheres and $1.3 \%$ for $900 \mathrm{~nm}$ spheres was established (Table 1). The error of sizing determined for the TDMPS in use during ASCOS is slightly larger than that reported by Mulholland et al. (2006) who states a 2\% deviation between SEM and TDMPS measurements for $100 \mathrm{~nm}$ PSL spheres.

Additionally for non-spherical particles $D_{\mathrm{m}}$ is a function of particle shape and orientation (DeCarlo et al., 2004). Nevertheless, previous studies (Rogak et al., 1993; Park et al., 2004) on diesel exhaust, $\mathrm{TiO}_{2}$ and $\mathrm{Si}$ particles have shown that $D_{\mathrm{m}} \sim D_{\mathrm{pa}}$ for non-spherical particles below $400 \mathrm{~nm}$. We can thus assume that the diameters obtained from TDMPS and SEM imaging are directly comparable and the error in the TDMPS measurements due to non-sphericity of any aerosol particles can be ignored.

\subsubsection{Discussion of Sample A}

The SEM derived aerosol size distribution for Sample A (Fig. 9, red line) shows number maxima in the Aitken mode at $42 \mathrm{~nm}$ and in the accumulation mode at $109 \mathrm{~nm}$ diameters. The simultaneous TDMPS measurement (Fig. 9, blue line) shows corresponding peaks at $34 \mathrm{~nm}$ and $133 \mathrm{~nm}$ diameters. The size determination of PSL spheres in the Aitken mode region revealed a standard deviation of $4.1 \mathrm{~nm}(18 \%)$ for $20 \mathrm{~nm}$ spheres and $4.1 \mathrm{~nm}(9.5 \%)$ for $40 \mathrm{~nm}$ spheres

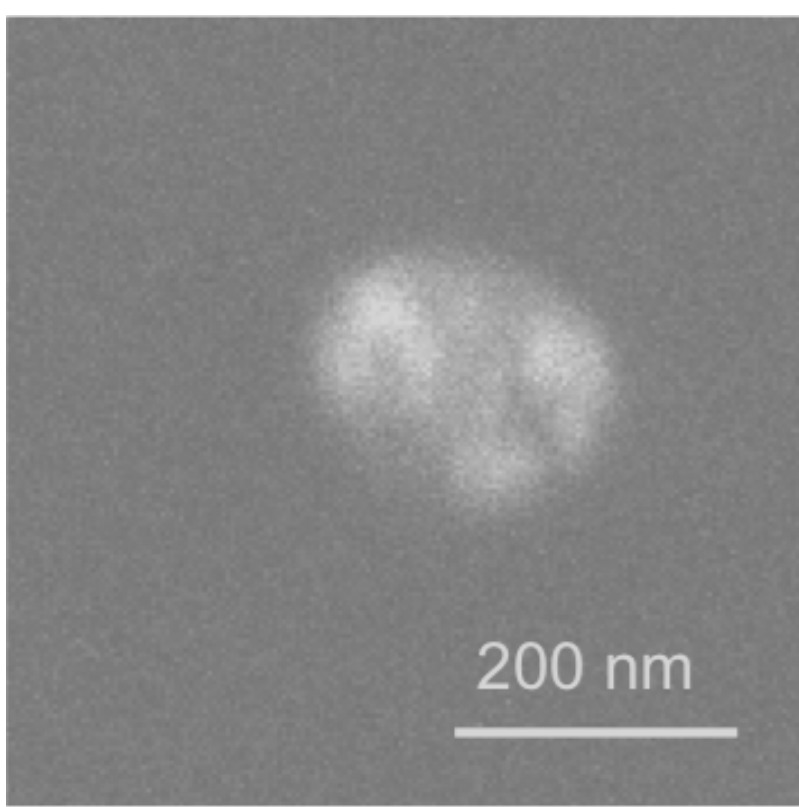

Fig. 12. An example for an ammonium sulfate particle which has partly collapsed under the electron beam but kept its outer shape.

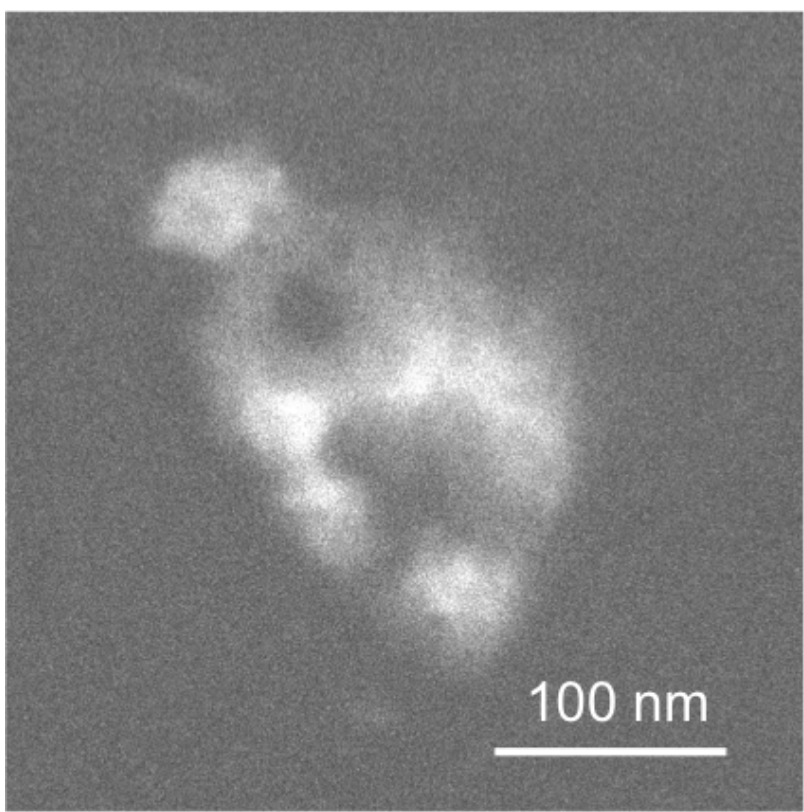

Fig. 13. An example for an aerosol particle with a patchy appearance and an inhomogeneous distribution of pixel intensity across the particle area (gel particle, GP).

(Table 1). If a standard deviation of ca. $14 \%$ for an ambient aerosol particles in the Aitken mode is assumed, and an at least $5 \%$ uncertainty (relative standard deviation) for the TDMPS measurements (Wiedensohler et al., 2012), the position of the Aitken mode peaks for the SEM and TDMPS derived diameters, $42 \mathrm{~nm}$ and $34 \mathrm{~nm}$, respectively, lies within 


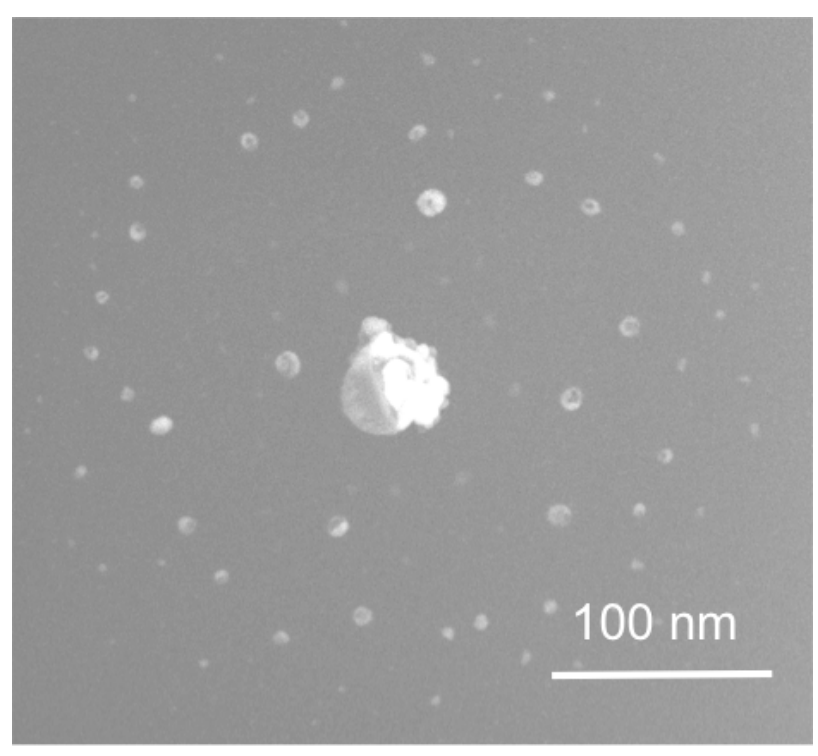

Fig. 14. An example for a satellite type structure of an aerosol particle (halo particle, HP). When the aerosol particle impacts on the TEM Formvar film it probably splashes out forming a number of small satellite particles surrounding a larger central core particle.

the statistical range of uncertainty determined for particles in this size range.

The accumulation mode maximum at $109 \mathrm{~nm}$ for the SEM derived size distribution corresponds to the TDMPS peak at $133 \mathrm{~nm}$ diameter. Using the standard deviation of the PSL sphere diameters in this size range, we can assume ca. $5 \%$ uncertainty for the aerosol particles in the accumulation mode for SEM derived diameters. We conclude that the position of the accumulation mode peaks for both SEM and TDMPS measurements at $109 \mathrm{~nm}$ and $133 \mathrm{~nm}$ do not lie within the statistical range of uncertainty determined for particles within this size range (see Fig. 9).

The differences in peak positions, however, suggest that the particles occurring at $133 \mathrm{~nm}$ diameter in the TDMPS size distribution is partly underestimated in the SEM measurements and their diameters are shifted towards the maximum at $109 \mathrm{~nm}$.

To improve the understanding of the causes for the observed shift in the position of accumulation mode maximum, we determined the morphological parameters elongation and circularity of the observed particle types (Table 2).

- Single particles (SP) appear in the 30-300 nm diameter size range and show a mean elongation of 0.334 and a mean circularity of 0.845 ; they comprise $85 \%$ of the total particle number.

- Gel particles (GP) appear mainly in the 70-322 nm diameter size range with a mean elongation of 0.639 and a circularity of 0.728 . They comprise $10 \%$ of the total particle number.
Table 2. Morphological parameters elongation and circularity with size ranges and number of particles for the observed particle types in Samples A and B.

\begin{tabular}{|c|c|c|c|c|}
\hline \multicolumn{5}{|c|}{ Single particles (SP) } \\
\hline & $\begin{array}{r}\text { Number of } \\
\text { particles }\end{array}$ & Size range & Elongation & Circularity \\
\hline Sample A & 310 & $30-300 \mathrm{~nm}$ & $0.334 \pm 0.08$ & $0.845 \pm 0.07$ \\
\hline Sample B & 307 & $30-300 \mathrm{~nm}$ & $0.176 \pm 0.090$ & $0.670 \pm 0.209$ \\
\hline \multicolumn{5}{|c|}{ Halo particles (HP) } \\
\hline & $\begin{array}{r}\text { Number of } \\
\text { particles }\end{array}$ & Size range & Elongation & Circularity \\
\hline Sample A & 19 & $116-227 \mathrm{~nm}$ & $0.14 \pm 0.067$ & $0.830 \pm 0.08$ \\
\hline Sample B & 23 & $51-233 \mathrm{~nm}$ & $0.090 \pm 0.05$ & $0.845 \pm 0.067$ \\
\hline \multicolumn{5}{|c|}{ Gel particles (GP) } \\
\hline & $\begin{array}{r}\text { Number of } \\
\text { particles }\end{array}$ & Size range & Elongation & Circularity \\
\hline Sample A & 36 & $70-322 \mathrm{~nm}$ & $0.639 \pm 0.077$ & $0.728 \pm 0.142$ \\
\hline Sample B & 32 & $70-532 \mathrm{~nm}$ & $0.212 \pm 0.089$ & $0.165 \pm 0.072$ \\
\hline
\end{tabular}

- Halo particles (HP) comprise $5 \%$ of the total particle number and their appearance is restricted to the accumulation mode region between 116-227 nm diameters. The central particles of the HP show a mean elongation of 0.140 and a circularity of 0.830 .

Due to the particle properties and the observed shift in the accumulation mode, it can be anticipated that the aerosol particle sizes are underestimated due to their partly very weak contrast with the background, especially for GP, and the difficulty to quantitatively capture all satellite particles of the HP. The overall size distributions, however, show similar peak intensities and positions for both methods.

Volatile organic compounds can evaporate under the electron beam (Gelencsér, 2004). Pósfai et al. (1998) discuss the evaporation of volatile compounds from ammonium sulfate aerosol particles at an accelerating voltage of $200 \mathrm{kV}$. They observed a decrease of the particle diameter by $20 \pm 5 \%$ and recognized a dark halo on the Formvar-coated Cu TEM grids marking the area around the particles where evaporation occurred. In our study an accelerating voltage of $2 \mathrm{kV}$ and Gentle Beam mode were applied. These very mild conditions were chosen to minimize the risk of evaporative losses and damaging of the aerosol particles through the electron beam. No signs of evaporation in form of halo-like shadows around the aerosol particles were observed in our study and thus evaporative loss of volatile organic compounds can be excluded as a cause for the observed differences in the position of the accumulation mode maximum in SEM and TDMPS size distributions.

\subsubsection{Discussion of Sample B}

Imaged by SEM, Sample B shows aerosol number maxima at $47 \mathrm{~nm}$ in the Aitken mode and at $122 \mathrm{~nm}$, with a shoulder 
at $200 \mathrm{~nm}$, in the accumulation mode (Fig. 10, red line). The corresponding TDMPS measurements show peak maxima in the Aitken mode at $52 \mathrm{~nm}$ and in the accumulation mode at $166 \mathrm{~nm}$ diameters (Fig. 10, blue line) and no visible shoulder to larger sizes. Assuming the same ranges of uncertainties as for Sample A, the Aitken mode maxima show good agreement of the peak positions in the SEM and TDMPS measurements. The accumulation mode on the other hand is shifted by $44 \mathrm{~nm}$ to smaller diameters in SEM compared to the TDMPS measurements and thus does not show any overlap. The aerosol particles and their morphological parameters showed the following characteristics:

- Single particles (SP) are observed between 30-300 nm diameters and account for $85 \%$ of the particle number. These particles type shows a mean elongation of 0.176 and a mean circularity of 0.670 .

- Gel particles (GP) are observed between 70 and $530 \mathrm{~nm}$ diameters and show an elongation of 0.212 and a circularity of 0.165 . They account for $10 \%$ of all aerosol particles in Sample B.

- Halo particles (HP) appear in the 50-230 nm diameter size range show an elongation of 0.090 and a mean circularity of 0.845 ; they account for $5 \%$ of the total particle number.

As for Sample A we assumed that the aerosol particle diameters can be underestimated due to their sometimes very weak contrast with the background, as in the case for GP and satellite particles of HP. But as for Sample A no signs of evaporative losses were observed. The overall size distribution shows a bimodal peak pattern and similar peak intensities for both methods.

\subsection{Comparison of Sample A and Sample B}

One of the most probable sources for aerosol particles in the Arctic is the surface water and specifically the surface micro-layer of the open water leads within the pack-ice region (Leck et al., 2002; Leck and Bigg, 2005a; Bigg and Leck, 2008; Orellana et al., 2011). The subsequent transformation processes the aerosol particles can undergo once they are airborne (e.g., through condensation of vapors) are important since they affect the aerosol's cloud droplet activation ability (Bigg and Leck, 2001b; Lohman and Leck, 2005; Martin et al., 2011).

Aerosol particles observed in both samples have been collected in air masses that spent different length of times over the pack-ice since last contact with the open sea. Provided that the MIZ is a strong source of aerosol particles, air masses with a short DOI ( 0.9 days, Sample A) carrying freshly emitted airborne aerosol particles favors a strong Aitken mode, whereas a long DOI (4.5 days, Sample B) leads to a more pronounced accumulation mode after days of processing in the air (Hoppel et al., 1986). Furthermore it has to be noticed that the difference between SEM and TDMPS derived peak diameters of the accumulation mode of Sample B $(44 \mathrm{~nm}$ in difference, Fig. 10) is much higher than that of Sample A ( $24 \mathrm{~nm}$ in difference, Fig. 9). This difference might be caused by a higher degree of underestimation of the particle area for GP and satellite particles of HP in Sample B due to the more weakly contrasting material present on the grid. Orellana and Verdugo (2003) showed that UV light destabilizes marine gels, and it might be possible that for longer DOI and thus a potentially longer exposure to UV light and other destabilizing factors has led to a weakening of the polymeric network and thus a decrease in density of the material that comprises the microgel in Sample B. We assume that this UV induced weakening of the polymeric might also lead to the generally larger peak diameters of the accumulation mode particles in Sample B (122 nm compared to $109 \mathrm{~nm}$ in Sample A).

In addition the morphological properties of the aerosol particles seem to change due to transport and transformation processes over the pack-ice. Circularity and elongation are both measures of the roundness of a particle, but elongation is predominantly an indicator of the overall form of a particle, whereas circularity is sensitive to both the overall form (like elongation) and surface roughness (via $\mathrm{CP}^{2}$; see above). Adding these parameters provides a more effective differentiator than a simple comparison of the size distributions of both samples.

- Single particles (SP): the values for elongation and circularity for SP in Sample A indicate (see Table 2) that the overall shape deviates from ideal sphericity to a larger extent than in Sample B. The SP in Sample B on the other hand exhibit a rougher contour than SP in Sample A:

- Elongation: with an elongation of 0.364 Sample A particles have a stronger elliptical component $\left(D_{\max }: D_{\min } \approx 2.00: 1\right)$ than Sample B particles with an elongation of $0.176\left(D_{\max }\right.$ : $D_{\min } \approx 1.42: 1$ ).

- Circularity: SP in Sample A shows a value for circularity of 0.845 , whereas for Sample B particles the value for circularity is 0.670 . Calculating the values for the Crofton perimeter (CP) for both samples reveals a $12 \%$ larger value for $\mathrm{CP}_{\mathrm{B}}$ with $\mathrm{CP}_{\mathrm{B}}: \mathrm{CP}_{\mathrm{A}}=1.12: 1$. The higher value for $\mathrm{CP}_{\mathrm{B}}$ and thus a lower value for circularity for $\mathrm{SP}$ in Sample B indicate particles with a rougher contour compared to particles in Sample A.

- Gel particles (GP): in SEM this type of aerosol particle shows a higher value for elongation in Sample A but particles with a higher deviation from ideal circularity and thus a rougher contour in Sample B.

- Elongation: in Sample A the GP are $18 \%$ more elongated with a value of 0.639 and with $D_{\max }$ : 
$D_{\min }=4.54$ compared to GP in Sample B where the elongation is 0.212 and the ratio of diameters is $D_{\max }: D_{\min }=1.54$.

- Circularity: GP in Sample B show a higher deviation from ideal circularity (0.165) compared to this type of particle in Sample A (circularity 0.728). The ratio of the Crofton parameters is $\mathrm{CP}_{\mathrm{A}}: \mathrm{CP}_{\mathrm{B}}=2.10: 1$ which indicates a rougher surface for GP in Sample B compared to Sample A particles.

- Halo particles (HP): the central particles exhibit nearly no differences in morphology for both samples. Both samples show moderate degrees of elongation and deviations from ideal circularity that do not indicate any differences due to a change in DOI.

- Elongation: the central particles in Sample A show a value for elongation of 0.14 and thus are slightly more elongated than the central particles in Sample B (elongation 0.09). The ratio of diameters $D_{\max }: D_{\min }$ is $1.33: 1$ for particles from Sample A, and $D_{\max }: D_{\min }=1.19: 1$ for particles from Sample B.

- Circularity: the circularity shows values of 0.83 for central particles of Sample A and 0.845 for Sample B. The ratio of the Crofton perimeter is calculated to $\mathrm{CP}_{\mathrm{A}}: \mathrm{CP}_{\mathrm{B}}=1.008: 1$ which indicates no significant differences in roughness for HP in both samples.

The size distributions for Sample A and B reveal some important differences which might be causally related to differences in time of advection over the ice before reaching the position of the icebreaker, providing that the type of marine sources was identical for both samples despite the geographically separated emission areas (Barents and Greenland seas respectively Kara sea, see Fig. 8). For the SP and GP type particles investigated in this study, we observed a transition from an elongated and branched particle to more a closed structure with increased DOI. The lower value in elongation for SP in Sample B points towards a process that changes the particle to be more round shaped which is favored by its longer DOI. The observed differences in circularity, however, indicated changes of the particles (GP and $\mathrm{SP}$ ) towards a larger surface area (expressed by an increased value for $\mathrm{CP}$ and a lower circularity) due to the longer DOI in Sample B. The surface of the particles did change towards a rougher contour (e.g., by condensation of vapors on the particle surface). Whether these morphological changes lead to changes in hygroscopicity and the incorporation of matter with surface-active properties, as it has been described for soot by Lehmann et al. (2006) and Coz and Leck (2011), deserves attention in future studies.

\section{Conclusions}

SEM operating at low accelerating voltage $(2 \mathrm{kV})$ and in Gentle Beam modus provides an optimal condition to size aerosol particles collected on a Formvar-coated $\mathrm{Cu}$ TEM grid with a resolution down to $15 \mathrm{~nm}$ diameter. The accuracy of our method was verified by measurement of certified PSL standard spheres and subsequent digital image analysis. The diameter values stated by the manufacturer were reproduced with high accuracy and morphological parameters (elongation, circularity) were determined. The standard deviation of the diameters was better than $10 \%$ for spheres larger than $40 \mathrm{~nm}$ and $\pm 18 \%$ for spheres of $21 \mathrm{~nm}$ diameter.

We applied our method to two samples of aerosol particles collected in the high Arctic during the ASCOS expedition in the summer of 2008. Size distributions as well as morphological parameters (elongation, circularity) were obtained for each sample. By comparing the size distributions with those from simultaneously and independently performed TDMPS measurements we demonstrated that a representative fraction of the ambient aerosol was captured with the same bimodal characteristics as in TDMPS. The method of SEM/image mapping of individual particles provides information not only on particle size but also on particle morphology, not seen by the TDMPS-method. Understanding particle morphology is important for an understanding of possible aerosol transformation processes in the atmosphere and the role of aerosol particles as embryos in cloud droplet activation.

However, using the digital image processing on weakly contrasting constituents bears the risk of underestimating the area of the projected particle. This limitation was observed in the accumulation mode as a shift of particle sizes to smaller diameters. This was seen for particles that were characterized by either an inhomogeneous distribution of intensity across the particle area (GP) or appear as a large central particle surrounded by smaller satellite particles (HP). However, its was fortunate that SP-type particles with their homogeneous distribution of intensity on the digital image contrasted well against their background and thus showed a good agreement in modal peak diameters with those measured by TDMPS.

Acknowledgements. This work is part of ASCOS (Arctic Summer Cloud Ocean Study) and was made possible by funding from the Swedish Research Council, the Knut and Alice Wallenberg Foundation and the DAMOCLES European Union 6th Framework Program Integrated Research Project. The Swedish Polar Research Secretariat (SPRS) provided access to the icebreaker Oden and logistical support. We are greatly indebted to Oden's Captain Mattias Peterson and his crew for invaluable assistance with all the logistical challenges. Michael Tjernström are specifically thanked for his co-coordination of ASCOS. ASCOS is an IPY project under the AICIA-IPY umbrella and an endorsed SOLAS project. The 
authors thank Andreas Held for collecting the particles during ASCOS 2008, and A. Öhrström and C. Rauschenberg for their help with sample imaging.

Edited by: I. Brooks

\section{References}

Allen, T.: Particle Size Measurement, Vol. 1, Chapman \& Hall, London, 1997.

Andreae, M. O. and Crutzen, P. J.: Atmospheric aerosols: biogeochemical sources and role in atmospheric chemistry, Science, 276, 1052-1058, 1997.

Baker, M. B.: Cloud microphysics and climate, Science, 276, 10721078, 1997.

Bates, T. S., Cline, J. D., Gammon, R. H., and Kelly-Hansen, S. R.: Regional and seasonal variations in the flux of oceanic dimethylsulfide to the atmosphere, J. Geophys. Res., 92, 2930-2938, 1987.

Bigg, E. K. and Leck, C.: Properties of the aerosol over the central Arctic Ocean, J. Geophys. Res., 106, 32101-32109, 2001a.

Bigg, E. K. and Leck, C.: Cloud active particles over the central Arctic ocean, J. Geophys. Res., 106, 32155-32166, 2001 b.

Bigg, E. K. and Leck, C.: The composition of fragments of bubbles bursting at the ocean surface, J. Geophys. Res. 113, D11209, doi:10.1029/2007JD009078, 2008.

Bigg, E. K., Leck, C., and Tranvik, L.: Particulates of the surface microlayer of open water in the central Arctic Ocean in summer, Mar. Chem., 91, 131-141, 2004.

Capannelli, G., Castello, E., Comite, A., Costa, C., and Mamolini, G.: Electron microscopy characterization of airborne micro- and nanoparticulate matter, J. Electron Microsc., 60, 117-131, 2011.

Charlson, R. J., Schwartz, S. E., Hales, J. M., Cess, R. D., Coakley Jr., J. A., Hansen, J. E., and Hofman, D. J.: Climate forcing by anthropogenic aerosol, Science, 255, 423-430, 1992.

Covert, D. S., Wiedensohler, A., Aalto, P., Heintzenberg, J., McMurry, P. H., and Leck, C.: Aerosol number size distributions from 3 to $500 \mathrm{~nm}$ diameter in the arctic marine boundary layer during summer and autumn, Tellus, 48B, 197-212, 1996.

Coz, E. and Leck, C.: Morphology and state of mixture of atmospheric soot aggregates during the winter season over Southern Asia - a quantitative approach, Tellus, 63B, 107-116, 2011.

Coz, E., Artínano, B., Robinson, A. L., Casuccio, G. S., Lersch, T. L., and Pandis, S. N.: Individual Particle Morphology and Acidity, Aerosol. Sci. Tech., 42, 224-232, 2008.

DeCarlo, P. F., Slowik, J. G., Worsnop, D. R., and Davidovits, P.: Particle morphology and density characterization by combined mobility and aerodynamic diameter measurements. Part 1: Theory, Aerosol Sci. Tech., 38, 1185-1205, 2004.

Dixkens, J. and Fissan, H.: Development of an Electrostatic Precipitator for Off-Line Particle Analysis, Aerosol. Sci. Tech., 30, 438-453, 1999.

Draxler, R. R. and Rolph, G. D.: HYSPLIT (HYbrid Single-Particle Lagrangian Integrated Trajectory) Model, NOAA ARL READY Website, available at: http://ready.arl.noaa.gov/HYSPLIT.php (last access: 15 May 2013), NOAA Air Resources Laboratory, Silver Spring, MD, 2011.

Facchini, M. C., Rinaldi, M., Decesari, S., Carbone, C., Finessi, E., Mircea, M., Fuzzi, S., Ceburnis, D., Flanagan, R., Nilsson, E.
D., de Leeuw, G., Martino, M., Woeltjen, J., and O'Dowd, C. D.: Primary submicron marine aerosol dominated by insoluble organic colloids and aggregates, Geophys. Res. Lett., 35, 1781417819, 2008.

Freedman, M. A., Baustian, K. J., Wise, M. E., and Tolbert, M. A.: Characterising the morphology of organic aerosols at ambient temperature and pressure, Anal. Chem., 82, 7965-7972, 2010.

Gelenscér, A.: Carbonaceous Aerosol, Springer, Dordrecht, The Netherlands, p. 167, 2004.

Haywood, J. M. and Boucher, O.: Estimates of the direct and indirect radiative forcing due to tropospheric aerosols: A review, Rev. Geophys., 38, 513-543, 2000.

Heard, M. and Wiffen, R.: Electron microscopy of natural aerosols and the identification of particulate ammonium sulphate, Atmos. Environ., 3, 337-340, 1969.

Heintzenberg, J. and Leck, C.: The summer aerosol in the central Arctic 1991-2008: did it change or not?, Atmos. Chem. Phys., 12, 3969-3983, doi:10.5194/acp-12-3969-2012, 2012.

Heintzenberg, J., Leck, C., Birmili, W., Wehner, B., Tjernström, M., and Wiedensohler, A.: Aerosol number-size distributions during clear and fog periods in the summer high Arctic: 1991, 1996 and 2001, Tellus B, 58, 41-50, 2006.

Hinds, W.: Aerosol Technology, 2nd Edn., John Wiley \& Sons, New York, 1999.

Hoppel, W. A., Frick, G. M., and Larson, R. E.: Effect of nonprecipitating clouds on the aerosol size distribution in the marine boundary layer, Geophys. Res. Lett., 13, 125-128, 1986.

Huck, D.: Particle shape - an important parameter in pharmaceutical manufacturing, Chem. Europe, available at: http://www. chemeurope.com, last access: 24 April 2013.

IPCC: Climate Change 2007: The Physical Science Basis, Contribution of Working Group I to the Fourth Assessment Report of the Intergovernmental Panel on Climate Change, edited by: Solomon, S., Qin, D., Manning, M., Chen, Z., Marquis, M., Averyt, K. B., Tignor M., and Miller, H. L., Cambridge University Press, Cambridge, New York, 2007.

Junge, C.: Die Konstitution des atmosphärischen Aerosols, Annalen der Meteorologie, 1-15, 1952.

Kandler, K., Benker, N., Bundke, U., Cuevas, E., Ebert, M., Knippertz, P., Rodriguez, S., Schuetz, L., and Weinbruch, S.: Chemical composition and complex refractive index of Saharan Mineral Dust at Izana, Tenerife (Spain) derived by electron microscopy, Atmos. Environ., 41, 8058-8074, 2007.

Karl, M., Leck, C., Coz, E., and Heintzenberg, J.; Marine nanogels as a source of atmospheric nanoparticles in the high Arctic, Geophys. Res. Lett., 40, 3738-3743, doi:10.1002/grl.50661, 2013.

Kerminen, V. M. and Leck, C.: Sulfur chemistry over the central Arctic Ocean during the summer: Gas-to-particle transformation, J. Geophys. Res., 106, 32087-32099, 2001.

Lannefors, H., Heintzenberg, J., and Hansson, H.-C.: A comprehensive study of physical and chemical parameters of the Arctic summer aerosol; results from the Swedish expedition Ymer-80, Tellus, 35B, 40-54, 1983.

Laskin, A., Cowin, J., and Iedema, M.: Analysis of individual environmental particles using modern methods of electron microscopy and X-ray microanalysis, J. Electron Spectrosc., 150, 260-274, 2006.

Leck, C. and Bigg, E. K.: Aerosol production over remote marine areas - A new route, J. Geophys. Res., 26, 3577-3580, 1999. 
Leck, C. and Bigg, E. K.: Biogenic particles in the surface microlayer and overlaying atmosphere in the central Arctic Ocean during summer, Tellus, 57B, 305-316, 2005a.

Leck, C. and Bigg, E. K.: Evolution of the marine aerosol - A new perspective, Geophys. Res. Lett., 32, L19803, doi:10.1029/2005GL023651, 2005b.

Leck, C. and Bigg, E. K.: Comparison of sources and nature of the tropical aerosol with the summer high Arctic aerosol, Tellus, 60B, 118-126, 2008.

Leck, C. and Bigg, E. K.: New particle formation of marine biological origin, Aerosol Sci. Tech., 44, 570-577, 2010.

Leck, C. and Persson, C.: Seasonal and short-term variability in dimethyl sulfide, sulfur dioxide and biogenic sulfur and sea salt aerosol particles in the arctic marine boundary layer during summer and autumn, Tellus, 48B, 272-299, 1996a.

Leck, C. and Persson, C.: The central Arctic ocean as a source of dimethyl sulfide: seasonal variability in relation to biological activity, Tellus, 48B, 156-177, 1996b.

Leck, C., Bigg, E. K., Covert, D. S., Heintzenberg, J., Maenhaut, W., Nilsson, E. D., and Wiedensohler, A.: Overview of the atmospheric research program during the International Arctic Ocean Expedition 1991 (IAOE-91) and its scientific results, Tellus, 48B, 136-155, 1996.

Leck, C., Nilsson, E. D., and Bäcklin, L.: The atmospheric program of the Arctic Ocean Expedition in the summer of 1996 (AOE96) - A technical overview - Outline of experimental approach, instruments, scientific objectives, J. Geophys. Res., 106, 3205132067, 2001.

Leck, C., Norman, M., Bigg, E. K., and Hillamo, R.: Chemical composition and sources of the high Arctic aerosol relevant for cloud formation, J. Geophys. Res., 107, 1-17, 2002.

Leck, C., Tjernström, M., Matrai, P., Swietlicki, E., and Bigg, E. K.: Can marine micro-organisms influence melting of the Arctic pack-ice?, Eos, 85, 25-36, 2004.

Lehmann, J., Gaunt, J., and Rodon, M.: Bio-char sequestration in terrestrial ecosystems - a review, Mitigation and Adaptation Strategies for Global Change, 11, 403-427, 2006.

Lohmann, U. and Feichter, J.: Global indirect aerosol effects: a review, Atmos. Chem. Phys., 5, 715-737, doi:10.5194/acp-5-7152005, 2005.

Lohmann, U. and Leck, C.: Importance of submicron surface active organic aerosols for pristine Arctic clouds, Tellus, 57B, 261-268, 2005.

Martin, M., Chang, R. Y.-W., Sierau, B., Sjogren, S., Swietlicki, E., Abbatt, J. P. D., Leck, C., and Lohmann, U.: Cloud condensation nuclei closure study on summer arctic aerosol, Atmos. Chem. Phys., 11, 11335-11350, doi:10.5194/acp-11-11335-2011, 2011.

McFarquhar, G. M., Um, J., and Jackson, R.: Small cloud particle shapes in mixed-phase clouds, J. Appl. Meteorol. Clim., 52, 1277-1293, doi:10.1175/JAMC-D-12-0114.1, 2013.

Meyer, F.: Mathematical Morphology: from two dimensions to three dimensions, J. Microsc., 165, 5-28, 1992.

Michael, J. R., Joy, D. C., and Griffin, B. J.: Use of sample bias voltage for low-energy high-resolution imaging in the SEM, Microsc. Microanal., 16, 614-615, doi:10.1017/S1431927610055315, 2010.

Mulholland, G. W., Donnelly, M. K., Hagwood, C. R., Kukuck, S. R., and Hackley, V. A.: Measurement of $100 \mathrm{~nm}$ and $60 \mathrm{~nm}$ parti- cle standards by differential mobility analysis, J. Res. Natl. Inst. Stan., 111, 257-312, 2006.

Nilsson, D. E. and Barr, S.: Effects of synoptic patterns on atmospheric chemistry and aerosols during the Arctic Ocean Expedition 1996, J. Geophys. Res., 106, 32069-32086, 2001.

Ocker, B., Wurster, R., and Seiler, H.: Investigation of nanoparticles in high resolution Scanning Electron Microscopy (SEM) and low voltage SEM by digital image analysis, Scanning Microscopy, 9, 63-73, 1995.

Orellana, M. V. and Verdugo, P.: Ultraviolet radiation blocks the organic carbon exchange between the dissolved phase and the gel phase in the ocean, Limnol. Oceanogr., 48, 1618-1623, 2003.

Orellana, M. V., Matrai, P. A., Leck, C., Rauschenberg, C. D., Lee, A. M., and Coz, E.: Marine microgels as a source of cloud condensation nuclei in the high Arctic, P. Natl. Acad. Sci., 108, 13612-13617, 2011.

Park, K., Kittelson, D. B., and McMurry, P. H.: Structural properties of diesel exhaust particles measured by transmission electron microscopy (TEM): relationships to particle mass and mobility, Aerosol Sci. Tech., 38, 881-889, 2004.

Parungo, F. and Nagamoto, C.: Temporal and spatial variations of marine aerosols over the Atlantic Ocean, Atmos. Res., 20, 23-37, 1986.

Poelt, P., Schmied, M., Obernberger, I., Brunner, T., and Dahl, J.: Automated analysis of submicron particles computer-controlled Scanning Electron Microscopy, Scanning, 24, 92-100, 2002.

Pósfai, M., Xu, H., Anderson, J. R., and Buseck, P. R.: Wet and dry sizes of atmospheric particles: An AFM-TEM study, Geophys. Res. Lett., 25, 1907-1910, 1998.

Rocha, S., Krastev, R., Thünemann, A. F., Pereira, M. C., Möhwald, H., and Bezesinski, G.: Adsorption of amyloid B-peptide at polymer surfaces: a neutron reflectivity study, Chem. Phys. Chem., 6, 2527-2534, doi:10.1002/cphc.200500158, 2005.

Rogak, S. N., Flagan, R. C., and Nguyen, H. V.: The mobility and structure of aerosol aggregates, Aerosol Sci. Tech., 18, 25-47, 1993.

Rolph, G. D.: Real-time Environmental Applications and Display sYstem (READY) Website, available at: http://ready.arl.noaa.gov (last access: 15 May 2013), NOAA Air Resources Laboratory, Silver Spring, MD, 2011.

Serra, J.: Image Analysis and Mathematical Morphology, Vol. 2: Theoretical Advances Academic Press, London, p. 309, 1988.

Shupe, M. D., Daniel, J. S., De Boer, G., Eloranta, E. W., Kollias, P., Long, C. N., Luke, E. P., Turner, D. D., and Verlinde, J.: A focus on mixed-phase clouds, B. Am. Meteorol. Soc., 89, 1549-1562, 2008.

Stevens, S. M., Jansson, K., Xiao, C., Asahina, S., Klingstedt, M., Grüner, D., Sakamoto, Y., Keiichi, M., Cubillas, P., Brent, R., Han, L., Che, S., Ryoo, R., Zhao, D., Anderson, M., Schüth, F., and Terasaki, O.: An Appraisal of High Resolution Scanning Electron Microscopy to Porous Material, JEOL news, 44, 17-22, 2009.

Stolzenburg, M. R.: An ultrafine aerosol size distribution measuring system, Ph. D. Thesis, Department, University of Minnesota, Minneapolis, USA, 1988.

Terasaki, O., Cho, H. S., Cho, M., Jeong, H. Y., Asahina, S., Sakuda, Y., Suga, M., Kazumori, H., Kudo, M., Nokuo, T., Liu, Z., Stevens, S. M., Anderson, M. W., GaleanoNunez D. C., Schüth, F., Kjellman, T., Alfredsson, V., Ha, L., Che, S., Deng, H., Yaghi, 
O., Cho, K., and Ryoo, R.: Novel structural characterisations of insulating and electron beam sensitive materials employing low voltage high resolution scanning electron microscopy, JEOL News, 48, 21-31, 2013.

Tjernström, M., Leck, C., Persson, P. O., Jensen, M., Oncley, S., and Targino, A.: The summertime arctic atmosphere: Meteorological measurements during the Arctic Ocean Experiment 2001 (AOE2001), B. Am. Meteorol. Soc., 85, 1305-1321, 2004.

Tjernström, M., Birch, C. E., Brooks, I. M., Shupe, M. D., Persson, P. O. G., Sedlar, J., Mauritsen, T., Leck, C., Paatero, J., Szczodrak, M., and Wheeler, C. R.: Meteorological conditions in the central Arctic summer during the Arctic Summer Cloud Ocean Study (ASCOS), Atmos. Chem. Phys., 12, 6863-6889, doi:10.5194/acp-12-6863-2012, 2012.

Tjernström, M., Leck, C., Birch, C. E., Brooks, B. J., Brooks, I. M., Bäcklin, L., Chang, R. Y.-W., Granath, E., Graus, M., Hansel, A., Heintzenberg, J., Held, A., Hind, A., de la Rosa, S., Johnston, P., Knulst, J., de Leeuw, G., Di Liberto, L., Martin, M., Matrai, P. A., Mauritsen, T., Müller, M., Norris, S. J., Orellana, M. V., Orsini, D. A., Paatero, J., Persson, P. O. G., Gao, Q., Rauschenberg, C., Ristovski, Z., Sedlar, J., Shupe, M. D., Sierau, B., Sirevaag, A., Sjogren, S., Stetzer, O., Swietlicki, E., Szczodrak, M., Vaattovaara, P., Wahlberg, N., Westberg, M., and Wheeler, C. R.: The Arctic Summer Cloud-Ocean Study (ASCOS): overview and experimental design, Atmos. Chem. Phys. Discuss., 13, 1354113652, doi:10.5194/acpd-13-13541-2013, 2013.

Twomey, S. A.: The Nuclei of Natural Cloud Formation. Part II: The Supersaturation in Natural Clouds and the Variation of Cloud Droplet Concentrations, Geofys. Pure Appl., 43, 227-242, 1959.
Wiedensohler, A., Covert, D. A., Swietlicky, E. S., Aalto, P., and Heintzenberg, J.: Occurrence of an ultrafine particle mode less than $20 \mathrm{~nm}$ in diameter in the marine boundary layer during the Arctic summer, Tellus, 48B, 213-222, 1996.

Wiedensohler, A., Birmili, W., Nowak, A., Sonntag, A., Weinhold, K., Merkel, M., Wehner, B., Tuch, T., Pfeifer, S., Fiebig, M., Fjäraa, A. M., Asmi, E., Sellegri, K., Depuy, R., Venzac, H., Villani, P., Laj, P., Aalto, P., Ogren, J. A., Swietlicki, E., Williams, P., Roldin, P., Quincey, P., Hüglin, C., Fierz-Schmidhauser, R., Gysel, M., Weingartner, E., Riccobono, F., Santos, S., Grüning, C., Faloon, K., Beddows, D., Harrison, R., Monahan, C., Jennings, S. G., O'Dowd, C. D., Marinoni, A., Horn, H.-G., Keck, L., Jiang, J., Scheckman, J., McMurry, P. H., Deng, Z., Zhao, C. S., Moerman, M., Henzing, B., de Leeuw, G., Löschau, G., and Bastian, S.: Mobility particle size spectrometers: harmonization of technical standards and data structure to facilitate high quality long-term observations of atmospheric particle number size distributions, Atmos. Meas. Tech., 5, 657-685, doi:10.5194/amt5-657-2012, 2012.

Whitby, K. T.: The physical characteristics of sulfur aerosols, Atmos. Environ., 12, 135-159, 1978.

Xin, L., Hede, T., Tu, Y., Leck, C., and Ågren, H.: Surface-active cis-pionic acid in atmospheric droplets: a molecular dynamics study, J. Phys. Chem. Lett. 1, 769-773, 2013. 